\title{
The psychosocial well-being of orphans in Southern Africa: the perception of orphans and teachers
}

\author{
$M W D E W_{I T T}{ }^{*} A N D A C \operatorname{LESSING}{ }^{* *}$
}

\begin{abstract}
The escalation in numbers of orphans in Sub-Saharan Africa has become a human catastrophe. If governments do not deal with this phenomenon as a priority it might spiral beyond control. Very few studies have been done to investigate the psychosocial impact of orphanhood on children and communities in developing countries. Very little is known about the life world of orphans in developing countries and even less is known about factors in these children's lives which can affect their mental health. The researchers decided to undertake research in three areas in Southern Africa to investigate the psychosocial well-being of orphans and to compare the findings with existing research findings. A survey was done in three rural areas to determine the perceptions of orphans regarding their own personal experiences and emotional feelings which may reflect on psychosocial well-being, as well as the perceptions of teachers working with these orphans. Except for depression, the findings with regard to most of the psychosocial aspects were in accordance with the literature. The most important findings were that bereavement practices and approaches fit for developed communities might be of little value in developing settings. We are, however, more than aware that orphans from developed counties or even urban settings might differ from those of developing or deep rural areas.
\end{abstract}

Key words: Orphans, psychosocial well-being, bereavement, poverty, stigmatisation.

\section{Introduction}

The escalation in numbers of orphans in Sub-Saharan Africa has become a matter of great concern. Already in 2005, an estimated $13.7 \%$ of South African children were maternal or double orphans of whom both parents passed away (Cluver \& Gardner, 2007, p. 318). It is estimated that by 2010, in 11 countries in Africa with a combined population of 109 million, $20-37 \%$ of children under 15 years of age will have lost one or both parents (Foster, 2002, p. $502)$.

It seems as if most research regarding this dilemma focuses on the physical and medical needs of the children left behind, and lesser studies have been done to investigate the psychosocial impact of orphanhood on children and communities in developing countries like Southern Africa (Foster, 2002, p. 502; Makame, Ani \& Grantham-McGregor, 2002, p. 460). Makame et al. (2002, p. 459) found that many orphans did not function as well as could be

\footnotetext{
Department of Teacher Education, Unisa. Pretoria, South Africa dwittmw@unisa.ac.za

Department of Educational Studies, Unisa. Pretoria, South/Africa lessiac@unisa.ac.za
}

TD The Journal for Transdisciplinary Research in Southern Africa, 6(2) December 2010, pp. 461 - 477. 
expected even when their material needs were adequately met and suggested that psychological problems may be responsible

Looking at psychosocial development implies looking at the relation of the individual's emotional needs to the social environment. In his theory Erikson provided "a framework for the understanding of the psychosocial needs of young people in relation to the society in which they grow up, learn and later make their contributions" (Woolfolk, 2010, p. 83). The emergence of the self, the search for identity, the individual's relationships with others and the role of culture throughout life are important aspects in psychosocial development. Temane and Wissing (2008, p. 106) indicate that various conditions in the environment within which a community exists play a role in the experience of well-being, "... well-being in rural communities is multidimensional arising from ecological, social, political, economic, and institutional factors." "They interpret well-being as the interrelated and interdependent structural and functional conditions of a community, including individuals and their interactions within their environment".

Social scientists predict that HIV/AIDS will not only restrict psychosocial development but also contributes to psychosocial distress like depression, anxiety and low self-esteem, due to the shock that results from the parent's death (Cluver, Gardner \& Don Operario, 2007, p. 757, 758; Ebersöhn \& Eloff, 2002, p.77, 82; Nyamukapa, Gregson, Lopman, Saito, Watts, Monasch \& Jukes, 2008, p. 133-134). The changes due to a parent's death may also be subtle and take place over time resulting in orphaned children developing "a sense of relative deprivation as their poorer circumstances coupled with stigma and discrimination result in their continually having reduced access to services and material resources" (Nyamukapa, et al. 2008, p. 134).

Psychosocial distress may result in increased insecurity, with future generations being brought up with limited social attachment to significant others. These adolescents seem to be caught between their fear of being found out and their wish to feel connected and to feel a sense of 'sameness' with their peers. Having to be protective of self and others may become barriers to constructing a healthy sense of intimacy (Reyland, Higgins-D'Alessandro \& Mcmahon, 2002, p. 291). This may also contribute to major impairments to their cognitive, social behaviour and moral functioning (Pharoah, 2004, p. 94). In their need for emotional security, the HIV/AIDS orphans may lack the ability to explore and make choices and may show signs of aggression, helplessness, sadness, depression and negative self-concepts. They may also present with disciplinary or behavioural problems (Nyamukapa, et al., 2008, p. 134).

It seems that although the occurrence of emotional and behavioural disturbances due to orphanhood have been tacitly acknowledged it have been ignored (Foster, 2002, p. 503). The crisis of children left behind is a humanitarian, developmental and human rights challenge of unprecedented proportions (Foster, 2005, p. 107).

Despite this looming crisis, the knowledge and skills related to child and adolescent mental health and their psychosocial needs have not been incorporated to the full in previous research on such orphans in developing countries. The potential value of such knowledge has largely been overlooked (Earls, Raviola \& Carlson, 2008, p. 296). Very little is known about the lifeworld of orphans in developing countries and even less is known about factors in these children's lives which can affect their mental health (Cluver \& Gardner, 2007, p. 318). Whatever happens with orphans after the death of their parents, the new structure and quality of children's living arrangements influences their future development (Hynes \& Dunifon, 
2007, p. 912). Nyamukapa, et al. (2008, p. 134) hypothesise that the death of a parent may result in short-term consequences like chronic trauma, adjustment problems, low future expectations, poor health, reduced school attendance and performance, school dorp-out, and even living on the streets.

The existing literature deals mainly with the psychosocial needs of orphans in developed countries which includes poverty, social skills, social cultural needs and psychosocial wellbeing, psychological problems and needs, self-esteem, emotional needs, loneliness, social withdrawal bereavement and stigmatisation (Cluver \& Gardner, 2007, p. 319; Foster 2005, p. 72; Karim \& Karim, 2005, p. 357; Robson \& Sylvester, 2007, p. 266; Waweru, Reynolds \& Buckner, 2008, p. 119; Zhao, Li, Fang, Zhao, Yang \& Stanton, 2007, p. 1075). Adolescents who do not have the requisite contexts and experiences for healthy identity development or who, because of severe stress and burdens fail to take on this task, may experience self-doubt and engage in self-destructive behaviours to relieve the anxiety associated with confusion (Reyland et al., 2002, p. 292). Psychosocial development implies amongst other aspects, the following: preparation of children for their entry into society and their constructive participation in social life and adherence to the evaluative norms that apply within their society; support to make independent choices and decisions, dealing with stress and managing their fears; the development of healthy mutual relations and dealings characterised by intimacy, attachment, caring, warmth, understanding, good humour, happiness, security and satisfaction; the development of awareness of the larger world outside the home and the encouragement of children's efforts to explore and control that world; assistance of children to develop self-discipline; assisting children to develop their own identity, which includes role models, gender role identity, group and cultural identity and career identity (Gerdes, 1988. p. 68; Louw \& Louw, 2007, p. 307; Mwamwenda, 1995, p. 429; Reyland et al., 2002, p. 286; Robson \& Sylvester, 2007, p. 266; Santrock, 2000, p. 345, 427; Smith, Bem \& Nolen-Hoeksema, 2001, p. 365; Wadeley, Birch \& Malim, 1997, p. 44).

Since very little is known about the psychosocial domain of orphans in Southern Africa the researchers decided to undertake research in three rural areas to investigate the psychosocial well-being of these orphans, as perceived by themselves and by teachers. The question can be asked: What is the perception of orphans and teachers of the psychosocial well-being of orphans and how do the findings concur with the literature?

\section{Research design and method}

A predominantly positivistic approach was followed to conduct a survey to determine the perceptions of teachers and orphans of the psychosocial well-being of orphans (Dash, 2008). The conceptual framework that guided the critical and integrative aspects of this cross sectional research (Earls et al., 2008, p. 296) was derived from research on orphans in developed countries as reflected in literature. Although in-depth interviewing would probably have provided rich descriptions and explanations of situational influences regarding lived experience of orphanhood (McMillan \& Schumacher, 2006, p. 197), the researchers decided to use questionnaires because of the large number of orphans in the target areas. In this way information about the perceptions of orphans as well as the perceptions of teachers working with these orphans could be obtained.

The researchers administered two different questionnaires to gather data on the participants' perception of their own feelings and situation with regard to psychosocial well-being as well as the perceptions of teachers regarding orphans' well-being (Cohen, Manion \& Morrison, 
2000, p. 244; Gay, Mills \& Airasian, 2006, p. 163). This article reflects only on some of the responses because of the magnitude of the survey.

Following an in-depth literature study, the researchers compiled the questionnaires to seek answers from teachers and orphans on psychosocial-related questions. A thorough literature study was done to establish how the orphans experienced their world and perceived their psychosocial well-being. Broad categories of factors contributing to psychosocial well-being were identified and included in the questionnaire. The results of the study will be discussed under these categories and compared with existing literature. The categories are poverty; social skills and socio-cultural needs and psychosocial well-being; self-esteem, emotional needs and psychosocial well-being; psychological problems and needs; bereavement. The nature of the questions was diverse, including biographical, physical, psychological and emotional issues. Open-ended questions were added to both questionnaires not only to gain rich descriptions and explanations of specific perceptions but also to understand from an epistemological perspective how the orphans made meaning of their world (Gall, Gall \& Borg, 2005, p. 28; Neuman, 2006, p. 110; Scheurich, 1997, p. 61) and an explorative, interpretive approach was used for the open-ended part of the questionnaire. The researchers realised that their own perceptions of reality do not only vary, but also differ greatly from the perceptions of the participants.

The one questionnaire investigated inter alia the perception of teachers of psychosocial aspects while the other questionnaire looked into the perception of the orphans. The questionnaire that addressed the orphans entailed three sections, namely A) biographical information, B) 24 questions on the psychosocial well-being with regard to psychosocial aspects, values and risk factors and $\mathrm{C}$ ) three questions with regard to their future vision. The second questionnaire, aimed at the perception of the teachers and entailed four sections: A) biographical information, B) five questions to determine the physical needs of the orphans as well as seventeen questions to determine the psychosocial needs of the orphans, C) seven questions aimed at the role of the school to support the orphans and D) four open-ended questions with regard to the culture and norms of the specific community. This article does not reflect on all the information gathered by the questionnaires.

Thus, the researchers chose a mixed-method mode of inquiry, involving a combination of quantitative and qualitative methods (De Vos, 2005, p. 346; Neuman, 2006, p. 110). The nature of the questions was diverse, ranking from structured to open-ended questions. A fourpoint Likert scale was used in the structured questions to determine the perceptions of the participants. Our questionnaire was constructed as an exploratory instrument to establish trends and has not been designed for extensive numerical treatment of data (Mouton, 2003, p.100). In order to identify potentially unclear instructions and items, the questionnaire was evaluated by an expert in research methods. Items that were unclear because of formulation as well as technical implications regarding data capturing were identified, and the formulation of a number of items was amended. The fieldworkers piloted the questionnaires in their areas with teachers and orphans and unclear items that arose because of formulation or structure, as well as those with technical implications regarding data capturing, were amended.

The necessary measures were taken to ensure validity and reliability of the questionnaires. Two measures of validity were considered when compiling the questionnaire, namely content validity and face validity (Delport, 2005, p. 161). The questionnaire measured what it was supposed to measure and the questions were adequate to be representative of the phenomenon. Steps had been followed to ensure the content validity of the questionnaire and 
included an extensive literature study and various experts checked the phrasing and assignments of items to fields.

\section{Aim of the empirical investigation}

The survey was developed to improve understanding of and describe the perception of teachers and orphans of the psychosocial well-being of orphans. The aim of this article is, however, not to compare whether orphans in developing countries have the same responses regarding their psychosocial well-being than orphans in developed countries, but rather to describe how orphans in a rural setting in the different areas perceive themselves. To answer the research question on the psychosocial well-being of orphans the following sub questions were formulated and served as the basis of the investigation: Do the orphans experience particular socio-cultural or psychological needs? Do they lack in social skills? What does their self-esteem look like? Do they have emotional needs because of their situation? Do they experience stigmatisation because of the fact that they are orphans? Do they experience physical or psychosocial needs? The answers to these questions were combined in the discussion to attend to: self-perception; risk factors; the children's view of the future and their perception of adulthood. The answers by the teachers were interpreted to understand and facilitate the questions asked to the orphans.

\section{Sample selection}

A convenient sampling was done, as the fieldworkers administered the questionnaires in the areas where they were working as the research was only done in certain areas in the Limpopo Province, North-West Province and Swaziland and thus the findings cannot be generalised. The group consisted of 637 orphans and 274 teachers. The researchers made use of three fieldworkers (one person with a doctorate in Psychology of Education and two doctoral students in Psychology of Education. All of them held senior official positions within the different departments of education in the three areas where the research took place. The fieldworkers did not know one another neither did they have any contact with one another while they were fieldworkers. Two of the three areas, namely Limpopo Province and the North-West Province, were in South Africa. The third area was in Swaziland. In collaboration with the officials of the Departments of Education, a number of schools were identified where the questionnaires could be distributed to all the orphans (Mouton, 2003, p. 100; Rossouw, 2003, p. 114). The following areas were included: Swaziland: Shiselweni, Manzini, Lobombo, Hhohho which include the whole of Swaziland; Limpopo: Mandlakazi and Leneyney; Rustenburg: the Bojanala region. The fieldworkers informed the orphans as well as the teachers working with the orphans how to complete the questionnaires. They also trained the teachers on how to complete the questionnaires on behalf of the young learners who could not read or write yet, and for some respondents in that area who had only functional literacy or were not able to read or speak English. The fieldworkers also fulfilled the role as interpreters, where necessary.

The number of schools involved, as well as the number of teachers and orphans, is presented in Table 1. 
Tables: Orphans in developing countries: What do their responses indicate?

Table 1. Number of schools, teachers and orphans involved

\begin{tabular}{|l|l|l|l|l|l|l|l|l|}
\hline \multicolumn{2}{|l}{ Limpopo } & \multicolumn{3}{l}{ North-West } & \multicolumn{2}{l|}{ Swaziland } \\
\hline School & Teachers & Orphans & School & Teachers & Orphans & School & Teachers & Orphans \\
\hline 1 & 21 & 29 & 1 & 16 & 45 & 1 & 7 & 20 \\
\hline 2 & 10 & 16 & 2 & 17 & 28 & 2 & 10 & 20 \\
\hline 3 & 13 & 70 & 3 & 12 & 38 & 3. & 16 & 42 \\
\hline 4 & 14 & 28 & 4 & 10 & 33 & 4 & 12 & 30 \\
\hline 5 & 18 & 27 & 5 & 13 & 22 & 5 & 8 & 30 \\
\hline & & & 6 & 16 & 27 & 6 & 8 & 35 \\
\hline 5 & & & 7 & 19 & 31 & 7 & 13 & 25 \\
\hline Total: & $\mathrm{n} 76^{* *}$ & $\mathrm{n} 170^{* *}$ & & $\mathrm{n} 120^{* *}$ & $\mathrm{n} 250^{* *}$ & & $\mathrm{n} 78^{* *}$ & $\mathrm{n} 217^{* *}$ \\
\hline
\end{tabular}

* Although there were orphans in the preschool, they were not selected.

** The " $n$ " totals for the different areas will be the same in all the tables to follow.

Regarding professional ethics, the researchers considered the following as important for this research (Mouton, 2003, p. 238): objectivity and integrity regarding the research; the way the data was recorded; the ethical principles underlying publication of the findings; participants' awareness of the purpose of the findings although the survey was anonymous. Participants also had the choice to participate and could withdraw whenever they wanted to (Gall et al., 2005, p. 136; Pellegrini, Symons, \& Hoch, 2004, p. 34).

According to Guba (in Poggenpoel, 1998, p. 331) and Mouton (2003, p. 107), the trustworthiness of the results of the qualitative section of the research can be increased by using appropriate fieldworkers. This was facilitated by using dependable and reliable qualified fieldworkers, specialising in Psychology of Education. The fieldworkers were familiar with the areas, cultural beliefs and languages (Tsonga, Pedi, Tswana and Swazi) used by the participants. The relationship of trust between the fieldworkers and the participants was a high priority set by the researchers. 


\section{Discussion of the literature and findings of the research}

A thorough literature study was done to establish how the orphans experienced their world and perceived their psychosocial well-being. Broad categories of factors contributing to psychosocial well-being were identified from the literature and included in the questionnaire. The results of the study will be discussed under these categories and compared with existing literature. The categories are poverty; social skills and socio-cultural needs and psychosocial well-being; self-esteem, emotional needs and psychosocial well-being; psychological problems and needs; bereavement.

\section{Poverty}

Literature on the physical state of orphans stresses the fact that poverty is a key cause of distress (Cluver \& Gardner, 2007, p. 219). The effect of parents' death and the financial situation of the children left behind is one of the major risks associated with childhood bereavement. It includes witnessing not only the traumatic death of their parents but also the subsequent financial instability of the children (Cluver \& Gardner, 2007, p. 319).

Poverty as a risk for emotional and behavioural distress, lack of food and resultant starvation is a concern for those working with orphans (Cluver \& Gardner, 2007, p. 321; Foster, 2002, p. 503). The lack of assets and material things make these children so obvious in the community and the school that they experience a sense of social exclusion and differentness (Cluver \& Gardner, 2007, p. 322). The fact that most orphans are not able to afford school fees, resources, uniforms and transport to school distresses them and makes them angry (Cluver \& Gardner, 2007, p.322). It is, however, evident that relatives or the community go to considerable lengths to find money to keep orphans in school and to maintain the children's socioeconomic status (Foster, 2002, p. 503).

The information presented in Table 2 regarding children's grants and foster care grants was part of the biographical information gathered during the survey.

\section{Table 2. Orphans who receive a grant}

\begin{tabular}{|l|l|l|l|}
\hline Area & $\begin{array}{l}\text { Children's grant } \\
\text { R210.00 }\end{array}$ & $\begin{array}{l}\text { Foster grant } \\
\text { R550.00 }\end{array}$ & Total \\
\hline Limpopo & $40.6 \%$ & $20.6 \%$ & $71.2 \%$ \\
\hline Northwest & $48.8 \%$ & $8.0 \%$ & $56.8 \%$ \\
\hline Swaziland* & $1.8 \%$ & $11.5 \%$ & $13.3 \%$ \\
\hline
\end{tabular}

* School fees are paid for all learners in Swaziland by the Premier

Though the children's grant of R210.00 is available for all children in South Africa, some orphans do not receive the grant because no adult (guardian) applies for it. Discussions with community leaders revealed that in many cases these grants are used for the whole family in whose care the orphans are, and not solely for the orphans themselves. From this information it is clear that a large number of orphans do not have any income or do not contribute financially to the family where they live. Access to the foster grant of R550.00 is often made 
difficult because the orphans do not have some family member (adult) who can or are willing to apply. The fact that some of the orphans do not have identity documents complicates matters.

The responses from the survey indicated that an average of $81 \%$ of orphans had identity documents. However, it seems as if the lack of parents' death certificates might be a problem, as only $61.1 \%$ of orphans were in a possession of death certificates of their deceased parents. These documents are prerequisites for applying for the foster grant.

The teachers who worked with orphans gave the following responses regarding the orphans' financial state (see Table 3):

Table 3. Teachers' perception of orphans' poverty expressed in lack of commodities

\begin{tabular}{|l|l|l|l|l|l|l|}
\hline Area & $\begin{array}{l}\text { Lack of } \\
\text { food }\end{array}$ & $\begin{array}{l}\text { Lack of } \\
\text { clothing }\end{array}$ & $\begin{array}{l}\text { Lack of } \\
\text { personal } \\
\text { hygiene }\end{array}$ & $\begin{array}{l}\text { Lack of } \\
\text { school funds }\end{array}$ & $\begin{array}{l}\text { Lack } \\
\text { school } \\
\text { material }\end{array}$ \\
\hline Limpopo & $82.1 \%$ & 87.7 & $85.0 \%$ & $83.6 \%$ & $76.7 \%$ \\
\hline $\begin{array}{l}\text { North- } \\
\text { West }\end{array}$ & $93.4 \%$ & $85.0 \%$ & $80.8 \%$ & $89.1 \%$ & $81.6 \%$ \\
\hline Swaziland & $92.0 \%$ & $89.7 \%$ & $66.6 \%$ & $94.3 \%$ & $75.9 \%$ \\
\hline Average & $89.1 \%$ & $87.4 \%$ & $77.4 \%$ & $89.0 \%$ & $71.4 \%$ \\
\hline
\end{tabular}

The frequencies of responses of the teachers (n274) to all the different factors resulting from poverty were very high. The effect of poverty on the psychosocial well-being of orphans cannot be ignored. Poverty surely contributes to low self-esteem and a feeling of being different from others who are better off. The relevant departments of social development will have to place some process of assuring that grants be distributed to orphans on their agenda.

\section{Social skills and socio-cultural needs and psychosocial well-being}

A number of researchers voice the concern that orphanhood may result in antisocial behaviour because the absence of role models makes it impossible for orphans to be socialised appropriately. According to Henderson (2006, p. 304), this is a debatable issue: because of the nature of family life and childcare in Southern Africa, children in this region have long been involved in fluid and extended family networks of care (Henderson, 2006, p. 311).

The loss of a parent will inevitably change the life of the child, and it will most likely bring about changes in roles and responsibilities (Murthy \& Smith, 2005, p. 4). The child might become the replaced parent for a number of siblings in child-headed households.

The theory of self-efficacy (Bandura 2004, in Earls et al., 2008, p. 299) allows for dynamic bidirectional interactions between the child and social actors, and spaces in the ecological surround. Therefore the orphan can be integrated into a system of psychological and social factors that can be observed, and are amenable to remedial and beneficial interventions that 
can address an orphan's own sense of efficacy and achieved psychosocial well-being (Earls et al., 2008, p. 299). In this sense the orphan can contribute to his/her own psychosocial wellbeing.

Though a lack of family contact is seen by many researchers as a risk factor, in the African context positive values are attached to the range of kin and even neighbours upon whom a child may call as role models and for support (Cluver \& Gardner, 2007, p. 321; Henderson, 2006, p. 306). As Africa places less emphasis on the individual and greater emphasis on extended families and communities, facilitators working in an African context will have to admit that western psychosocial treatment models used inappropriately in non-western settings do not necessarily work (Foster, 2002, p. 504).

One can assume that factors promoting psychosocial well-being would, as in developed countries, include universal safety and security: sympathetic caregivers; familiar routines and tasks and interaction with other children. However, Foster (2002, p. 504) gives the following worthwhile advice: a community-based approach encourages self-help and builds on local resources, culture, realities and authentic perceptions of child development. Psychological support in an African context should be strategically integrated into community-based programmes that provide support to children.

Table 4. Responses on how orphans experience their own situation regarding the death of their parents

\begin{tabular}{|l|l|l|l|}
\hline Area & $\begin{array}{l}\text { I feel lost because I do } \\
\text { not have parents. }\end{array}$ & $\begin{array}{l}\text { I blame myself for my } \\
\text { parents' death. }\end{array}$ & $\begin{array}{l}\text { I feel afraid that I will } \\
\text { be removed from my } \\
\text { home. }\end{array}$ \\
\hline Limpopo & $57.6 \%$ & $41.2 \%$ & $41.8 \%$ \\
\hline North-West & $42.8 \%$ & $24.8 \%$ & $41.6 \%$ \\
\hline Swaziland & $35.5 \%$ & $20.8 \%$ & $41.9 \%$ \\
\hline Total & $45.3 \%$ & $28.9 \%$ & $41.7 \%$ \\
\hline
\end{tabular}

Orphans in the Limpopo Province ranked the highest (57.6\%) in feeling lost because they did not have parents, and $41.2 \%$ blamed themselves for their parents' death. An average of $41.7 \%$ orphans felt afraid that they would be removed from their homes. These feelings may contribute to psychosocial distress and result in depression (Nyamukapa, et al., 2008, p. 134).

\section{Psychological problems and needs}

A study done by Foster (2002, p. 503) found substantial evidence of reduced psychological well-being, with most orphans showing psychological impairment, especially internalised changes in behaviour, such as depression, anxiety and low self-esteem. Makame et al. (in Foster 2002, p. 503) goes even further by claiming that children living in child-headed households or with grandparents have the most serious psychological problems. Cluver et al. (2007, p. 758) found that when controlling for age and female gender, orphanhood by AIDS 
was significantly related to higher depression scores while orphanhood due to other causes was not necessarily associated with depression.

Other researchers highlighted anger and grief for teenage heads of child-headed households (Cluver \& Gardner, 2007, p. 21). Makame et al. (in Foster 2002, p. 503) state that it is difficult to determine the severity of orphans' psychological problems and that many orphans had not grieved or come to terms with the death of their parents. The presence of caring and supportive families support orphans and enable them to withstand severe psychological stress (Foster 2002, p.503). Table 5 depicts the perception of teachers regarding orphans' feelings of stress and depression.

Table 5. Teachers' perception of orphans experiencing depression

\begin{tabular}{|l|l|l|l|}
\hline Area & Feelings of sadness & $\begin{array}{l}\text { Feelings of } \\
\text { depression }\end{array}$ & Feelings of helplessness \\
\hline Limpopo & $80.8 \%$ & $76.7 \%$ & $80.9 \%$ \\
\hline North-West & $9.2 \%$ & $19.1 \%$ & $9.2 \%$ \\
\hline Swaziland & $39.1 \%$ & $40.2 \%$ & $36.7 \%$ \\
\hline Total & $43.0 \%$ & $45.3 \%$ & $42.2 \%$ \\
\hline
\end{tabular}

Once again the variance between the three localities was very big. In the Limpopo Province teachers interpreted orphans' feelings as experiencing excessive stress and depression because of their situation. It was the contrary in North-West Province, where teachers were under the impression that orphans experience very little stress and depression because of their parents' death. There is no logical clarification for this except that the communities in the Limpopo area are desperately poor. Furthermore, it is important to attend to orphans' feelings of sadness, depression and helplessness even if only few learners are perceived as experiencing problems, as these feelings hamper the psychosocial well-being of the learners.

Table 6. Teachers' perception of orphans manifesting behaviour problems

\begin{tabular}{|l|l|l|l|}
\hline Area & $\begin{array}{l}\text { Experience } \\
\text { behavioural problems }\end{array}$ & $\begin{array}{l}\text { Experience } \\
\text { aggression }\end{array}$ & $\begin{array}{l}\text { Experience disciplinary } \\
\text { problems }\end{array}$ \\
\hline Limpopo & $80.9 \%$ & $61.6 \%$ & $64.4 \%$ \\
\hline North-West & $28.3 \%$ & $24.1 \%$ & $28.3 \%$ \\
\hline Swaziland & $40.2 \%$ & $52.9 \%$ & $45.9 \%$ \\
\hline Total & $49.8 \%$ & $46.2 \%$ & $46.2 \%$ \\
\hline
\end{tabular}


Once again it is interesting that there is quite a variance in the perceptions of the teachers in the different localities regarding orphans' behavioural problems and aggression. It seems as if teachers in Swaziland and those in the North-West Province experienced orphans as being far less aggressive and as demonstrating less problem behaviour than teachers in the Limpopo Province did. It is, however, important to note that stressors of utmost poverty in the Limpopo area might have caused the difference. Teachers need to attend to unacceptable behavioural patterns of the orphans as the behavioural problems may negatively influence the social relations and interaction of the learners.

\section{Self-esteem, emotional needs and psychosocial well-being}

The lack of material possessions surely contribute to low self-esteem within orphans (Foster, 2002 , p. 503). The death of loved ones and the resulting grief amplifies and complicates the typical strains of a happy childhood and careless early adolescence (Murthy \& Smith, 2005, p. ix). It is human for children to become depressed when their parents fall ill and all signs are there that they are going to die. The bleak future and the fear of not getting a job and living a normal life influence orphans' outlook on the future (DeVane Fair, 2006, p 357; Foster, 2002, p. 503).

Like any other children, orphans value being loved, getting attention, commanding respect, being wanted, and having fun with caregivers who set boundaries for them (Cluver \& Gardner, 2007, p. 321). Research has shown that orphans feel unhappy when they are treated differently from their siblings in the new family (Cluver \& Gardner, 2007, p. 321). Tables 710 reflect the responses of orphans regarding their own happiness and interpretation of their future, which are important factors in reaching psychosocial well-being.

Table 7. Orphans' responses regarding their own future and feeling of happiness

\begin{tabular}{|l|l|l|l|l|}
\hline & Limpopo & North-West & Swaziland & Average \\
\hline I want to become a grown-up. & $92.4 \%$ & $88.0 \%$ & $96.3 \%$ & $92.2 \%$ \\
\hline I cope with my present situation. & $70.6 \%$ & $62.8 \%$ & $68.7 \%$ & $67.3 \%$ \\
\hline I have hope for my future. & $88.2 \%$ & $82.0 \%$ & $95.4 \%$ & $88.5 \%$ \\
\hline I can influence my own future. & $88.8 \%$ & $70.0 \%$ & $79.7 \%$ & $79.5 \%$ \\
\hline I am happy about the future. & $62.4 \%$ & $74.8 \%$ & $89.0 \%$ & $75.4 \%$ \\
\hline $\begin{array}{l}\text { I am experiencing an inner feeling of } \\
\text { happiness. }\end{array}$ & $71.8 \%$ & $58.4 \%$ & $71.9 \%$ & $67.3 \%$ \\
\hline
\end{tabular}

On questions related to the future as well as to personal happiness the responses of the orphans in the survey were quite positive. From this survey it is clear that most of the orphans are not necessarily negative about their future and do experience inner feelings of happiness. Though there were orphans who indicated negative feelings the overwhelming responses were positive which is quite contrary to what is expressed in the literature. 
In the open-ended questions orphans indicated that most of them see themselves as having a profession, earning a decent salary, getting married and having their own family. Occupations like policemen, nurses, social workers and teachers ranked high in the list of preferred occupations. In spite of their problematic situation orphans indicated a view for the future.

\section{Bereavement}

Bereavement in the African context might be totally different from what is experienced in developed countries. The taboo of discussing death has been noted by researchers working in developing countries and communities (Cluver \& Gardner, 2007, p. 319). This might result in a different approach for facilitators to build a culture of mutual aid or experience within the bereavement support group (Murthy \& Smith, 2005, p. xi). The feeling of not being alone and knowing that others experience the same thoughts and feelings as they do, might help them to deal with the sorrow (Murthy \& Smith, 2005, p. xi). However, Henderson (2006, p. 306) finds it preferable in the African context for children and young people to choose at what point they deem it appropriate to speak of such things, if at all.

Although orphans' anecdotes as quoted by Cluver and Gardner (2007, p. 320) reflect their sorrow and distress as a result of the death of both parents and other family members (Cluver \& Gardner, 2007, p 319), as well as their guilt at feeling responsible for the death of their parents, they also felt that happiness would come from "having parents alive to take care of me" and "[i]f I see my dead parents again". It would be of great importance to know if the stages of bereavement, namely, shock, grief, guilt and acceptance (Kübler-Ross, (no date) would apply to orphans in developing countries.

The following tables give the responses of the orphans regarding their experience of their situation and their own feelings.

Table 8. Orphans' responses on how they deal with their circumstances

\begin{tabular}{|l|l|l|l|}
\hline Area & $\begin{array}{l}\text { I am afraid in } \\
\text { unfamiliar situations. }\end{array}$ & $\begin{array}{l}\text { I am angry about } \\
\text { my situation. }\end{array}$ & $\begin{array}{l}\text { Other people understand } \\
\text { my feelings. }\end{array}$ \\
\hline Limpopo & $55.9 \%$ & $63.6 \%$ & $76.5 \%$ \\
\hline North-West & $61.3 \%$ & $50.4 \%$ & $60.8 \%$ \\
\hline Swaziland & $58.0 \%$ & $50.3 \%$ & $70.1 \%$ \\
\hline Average & $58.4 \%$ & $54.7 \%$ & $69.1 \%$ \\
\hline
\end{tabular}

An average of $54.7 \%$ of orphans experienced a feeling of anger regarding their situation. It is not clear whether the feeling of anger can be seen within the theoretical framework of bereavement as postulated by Kübler-Ross (no date). Caregivers should attend to the grief of orphans as Cluver et al. (2007, p. 761) suggest that "AIDS-related parental bereavement can contribute to heightened levels of internalizing and some externalising distress". 
Table 9. Orphans' responses on how they deal with their circumstances (continued)

\begin{tabular}{|l|l|l|l|}
\hline Area & $\begin{array}{l}\text { I talk about my grief } \\
\text { and sorrow with other } \\
\text { people. }\end{array}$ & $\begin{array}{l}\text { I share my feelings } \\
\text { with others. }\end{array}$ & $\begin{array}{l}\text { I am still grieving } \\
\text { about the death of my } \\
\text { parents. }\end{array}$ \\
\hline Limpopo & $57.6 \%$ & $88.2 \%$ & $60.6 \%$ \\
\hline North-West & $43.6 \%$ & $53.6 \%$ & $69.6 \%$ \\
\hline Swaziland & $66.3 \%$ & $79.3 \%$ & $54.8 \%$ \\
\hline Average & $55.8 \%$ & $73.7 \%$ & $61.6 \%$ \\
\hline
\end{tabular}

There is quite a variance between the responses of orphans in the different areas. Orphans in Limpopo indicated that the majority $(88.2 \%)$ could share their feelings with others while in the North-West province only $53.6 \%$ could do so. An average of $61.6 \%$ of orphans still grieved about the death of their parents during the research.

\section{Stigmatisation}

Campbell, Foulis, Maimane and Sibiya (2005, p. 808) see stigmatisation as an effective form of "social psychological policing" by punishing those who have breached unequal power relations of gender, generation, and ethnicity. Surely stigmatisation is one of the major problems for orphans nowadays. Literature reflects a very negative experience by those affected by the death of relatives (Brown, Macintyre, \& Trujillo, 2003, p. 51). The sources of stigma may include factors like fear of illness or contagion as well as fear of death (Brown et al., 2003, p. 51). Orphans experience gossip and stigma as a great problem and talking about the death of parents and spreading rumours about the reasons for the death is a burden for those staying behind (Cluver \& Gardner, 2007, p. 323). Children drop out of school not only because they do not have school fees, or money to buy books and uniforms, but very often because of stigma (Ebersöhn \& Eloff, 2002, p.79; Foster 2005, p. 72).

To address the problem of stigmatisation, community networks will have to become part of the solution. This point of view is endorsed by Campbell et al., $(2005$, p. 811) who indicate that much has been written about the roles of "civic engagement" and "local solidarity as key assets in poor communities" to find solutions to their own problems as united communities.

Questions to underpin the issue of stigmatisation were formulated and the responses of orphans are reflected in Table 12. 


\section{Table 10. Orphans' responses on their experience of stigmatisation}

\begin{tabular}{|l|l|l|}
\hline Area & $\begin{array}{l}\text { People think I am different } \\
\text { because I don't have parents }\end{array}$ & $\begin{array}{l}\text { I prefer to keep it secret that I } \\
\text { do not have parents }\end{array}$ \\
\hline Limpopo & $45.3 \%$ & $43.6 \%$ \\
\hline North-West & $46.0 \%$ & $45.2 \%$ \\
\hline Swaziland & $40.6 \%$ & $36.4 \%$ \\
\hline Total & $43.9 \%$ & $41.7 \%$ \\
\hline
\end{tabular}

The responses regarding stigmatisation were not alarmingly high. Orphans in the North-West Province were the highest, with $46.0 \%$ agreeing that they experience a feeling of differentness and $45.2 \%$ saying that they would like to keep it a secret that they do not have parents. Silence is encouraged primarily because HIV infection has been socially constructed as a product of moral or character deficiency. Especially adolescents may feel guilty as result of the disclosure of their mother's HIV status, resulting in feelings of shame and anger (Reyland et al., 2002, p. 286).

\section{Conclusion}

Caution reflected by different researchers that can be supported by us is that one needs to distinguish which factors are specific to orphanhood, or to poverty in general (Cluver \& Gardner, 2007, p. 324; Henderson, 2006, p. 305). The research was done in very deep rural areas in which poverty is rampant. The authorities will have to assist the communities in addressing this issue of poverty as a matter of urgency.

As very little literature or research findings are available regarding orphans in developing countries, we did not have any statistical findings against which we could reflect our findings. We are, however, more than aware that circumstances as well as outlook on life of orphans from developed countries or even urban settings might differ from those of developing or deep rural areas.

When working with these children, facilitators, caregivers and researchers should pay special attention to the context and cultural beliefs and practices of the communities in which they work. Bereavement practices and approaches fit for developed communities might be of little value in developing settings.

One of the assets of the African context is surely the role of the extended family and the community in supporting those who are left behind. Even the way the dead are closely folded into the living world through their burial in homesteads, and through rituals that transform them into ancestral followers who, it is believed, continue to take a keen interest in the affairs of the living, cannot be denied (Henderson, 2006, p. 322).

It is interesting that within a Southern African perspective an average of $41.7 \%$ orphans feel afraid that they would be removed from their homes. This once again emphasises the fact that institutional options for orphans are not necessarily the answer in this context. 
The findings from this survey are a clear indication that findings from research done in rural areas should not necessarily be the same for orphans living in developed countries or urban areas. People working with orphans in these areas will have to do thorough, authentic research before they intervene in the lives of members of these communities. The strong presence of mutual and cultural support systems needs to be interrogated by those who want to help.

\section{Bibliography}

Brown, L., Macintyre, K. \& Trujillo, L. 2003. Interventions to reduce HIV/AIDS stigma: What have we learned. AIDS Education and Prevention, 15(1), 49-69. The Guildford Press.

Campbell, C., Foulis, C.A., Maimane, S. \& Sibiya, Z. (2005). "I Have an Evil Child at My House": Stigma and HIV/AIDS Management in a South African Community. Public Health Matters. American Journal of Public Health. May, 2005. 95(5), 808-815.

Cluver, L. \& Gardner, F. (2007). Risk and protective factors for psychological well-being of children orphaned by AIDS in Cape Town: a qualitative study of children and caregivers, perspectives. AIDS Care. March 2007, 19(3), 318-325.

Cluver, L. Gardner, F. \& Operario, D. (2007). Psychological distress amongst AIDSorphaned children in urban South Africa. Journal of Child Psychology and Psychiatry, 48(8), 755-763.

Cohen, C., Manion, L. \& Morrison, K. (2000). Research methods in education. (5 ${ }^{\text {th }}$ ed.). London: Routledge.

Dash, N.K. 1993. IGNOU Online Research Methods Resource for Teachers and Trainers. Internet Files\Content. Outlook\NM9H1MAZ\Research Methods Resource - Selection of the Research Paradigm and Methodology.mht (Accessed May 2008).

Delport, C.S.L. (2005) Quantitative data collection methods. In: De Vos, A.S., Strydom, H., Fouché, C.B. \& Delport, C.S.L. (eds.), Research at grass roots for the social sciences and human service professions (3rd ed.). Pretoria: Van Schaiks, 159-191.

DeVane Fair, C. (2006). The Emotional and Educational Functioning of Children Living with Maternal HIV/AIDS and Substance Use. Child and Adolescent Social Work Journal, 23(3), 356 -374.

De Vos, A.S. (2005) Qualitative data analysis and interpretation. In: De Vos, A.S., Strydom, H., Fouché, C.B. \& Delport, C.S.L. (eds.). Research at grass roots for the social sciences and human service professions (3rd ed.). Pretoria: Van Schaiks, 333-356.

Earls, F. E., Raviola, G.J. \& Carlson, M. (2008). Promoting child and adolescent mental health in the context of the HIV/AIDS pandemic with a focus on sub-Saharan Africa. Journal of Child Psychology and Psychiatry, 49(3), 295-312.

Ebersöhn, 1. \& Eloff, I. (2002). The black, white and grey of rainbow children coping with HIV/AIDS. Perspectives in Education, 20(2), 77-86.

Foster, G. (2002). Beyond education and food: psychosocial well-being of orphans in Africa. ACTA PEADIATR. 91, 502-504.

Foster, G. (2005). A generation at risk? The global impact of HIV/AIDS on orphans and vulnerable children. Cambridge: University Press.

TD, 6(2), December 2010, pp. 461 - 477. 
Gall, J.P. Gall, M.D. \& Borg, W.R. (2005). Applying Educational Research. A Practical Guide. ( $5^{\text {th }}$ ed.). New York: Pearson.

Gay, L.R., Mills, G.E. \& Airasian, P. (2006). Educational Research. Competencies for Analysis and Applications. ( $8^{\text {th }}$ ed.). Pearson: Merrill Prentice Hall.

Gerdes, L. (1988). Die ontwikkelende volwassene. (2de uitgawe). Butterworths: Durban.

Henderson, P.C. (2006). South African AIDS Orphans: Examining assumptions around vulnerability from the perspective of rural children and youth. Childhood, 13, 303327.

Hynes, K. \& Dunifon, R. (2007). Children in no-parent households: The continuity of arrangements and the composition of households. ScienceDirect. Children and Youth Services Review. 29 (2007) 912-932. www.sciencedirect.com

Karim, S.S.A. \& Karim, Q.A. 2005. HIV/AIDS in South Africa. London: Cambridge University Press.

Kübler-Ross, E. (No date) (1926-2004). Retrieved 2 May 2008 from Changingminds.org/disciplines.change_management/kubler_ross/kubler_ross.htm (Accessed May 2008).

Louw, D. \& Louw, A. (2007). Die ontwikkeling van die kind en die adolessent. Bloemfontein: Universiteit van die Vrystaat.

Makame, V., Ani, C. \& Grantham-McGregor, S. (2002). Psychological well-being of orphans in Dar El Salaam, Tanzania. Acta Pcediatr, 9, 459-465.

McMillan, J.H. \& Schumacher, S. (2006). Research in Education. Evidence-Based Inquiry. $\left(6^{\text {th }}\right.$ ed.). New York: Pearson.

Mouton, J. (2003). How to succeed in your master's and Doctoral Studies. A South African Guide and Resource Book. Pretoria: Van Schaik.

Murthy, R. \& Smith, L. (2005). Grieving, Sharing, and Healing. A Guide for Facilitating Early Adolescent Bereavement Groups. Champaign: Research Press.

Neuman, W.L. (2006). Social Research Methods. Qualitative and Quantitative approaches. ( $6^{\text {th }}$ ed.). New York: Pearson.

Nyamukapa, C.A., Gregson, S., Lopman, B., Saito, S., Watts, H.J., Monasch, R. \& Jukes, M.C.H. (2008). HIV-associated Orphanhood and Children's Psychosocial distress: Theoretical Framework Tested with Data from Zimbabwe. American Journal of Public Health. 98(1), 133- 141.

Pellegrini, A.D., Symons, F.J. \& Hoch, J. (2004). Observing Children in Their Natural Worlds. A mythological Primer. ( $2^{\text {nd }}$ ed.). London: Lawrence Erlbaum Associates.

Pharaoh, R. (2004). A Generation at Risk? HIV/AIDS, vulnerable children and security in Southern Africa. Pretoria: Institute for Security Studies.

Poggenpoel, M. (1998). Data analysis in qualitative research. In A.S. de Vos (Ed.): Research at grass roots. A primer for the caring professions. Pretoria: Van Schaik: 331-336.

Reyland, S.A., Higgins-D’Alessandro, A. \& Mcmahon, T.J. (2002). Tell them you love them because you never know when things could change: voices of adolescents living with HIV-positive mothers. Aids Care, 4(2), 285-294. 
Robson, S. \& Sylvester, K.B. (2007). Orphaned and vulnerable children in Zambia: the impact of the HIV/AIDS epidemic on basic education for children at risk. Journal of Child Psychology and Psychiatry, 48:8, 755-763.

Rossouw, D. (ed.) (2003). Intellectual Tools: Skills for the human sciences. (2nd ed.) Cape Town: Creda Communications.

Santrock, J. (2000). Psychology. (6th ed.). McGraw-Hill: New York.

Scheurich, J.J. (1997). Research method in the postmodern. London: Falmer.

Smith, E.E., Bem, D.J. \& Nolen-Hoeksema, S. (2001). Fundamentals of psychology. Harcourt College: New York.

Temane, Q.M. \& Wissing, M.P. 2008. The Role of Personality Factors in the Dynamics of Context and Psychological Well-Being. Journal of Psychology in Africa. 18(1), 105114.

Wadeley, A., Birch, A. \& Malim. T. (1997). Perspectives in psychology. London: MacMillan.

Waweru, S.M., Reynolds, A. \& Buckner, E.B. (2008). Perceptions of Children with HIV/AIDS from the USA and Kenya: Self-Concept and Emotional Indicators. Pediatric Nursing, 34(2), 119.

Woolfolk, A. (2010). Educational Psychology. (11 ${ }^{\text {th }}$ ed.). Upper Saddle River: Pearson International.

Zhao, G., Li, X., Fang, X., Zhao, J., Yang, H. \& Stanton, B. (2007). Care arrangements, grief and psychological problems among children orphaned by AIDS in China. AIDS Care, 19(9), 1075-1082. 